Pearson gives in many extensive digressions is not, I think, successfully integrated into the discussion of the development of statistical methods. Bibliographical details are generally given accurately, but references to even those secondary sources available to Pearson are scarce. But these are all minor problems compared with the rare opportunity we have been given to sit at the feet of this energetic and learned professor as he takes us on a personalised tour of statistical history, and we often learn as much in the process about Pearson as we do of his subject. Here Pearson speaks of a table of Simpson's as "probably faked" (page 387); there Pearson laments that the brains of Lagrange and Laplace were not preserved for later study (page 585); and there Pearson faults Euler for failure to compile numerical tables "which would energise

\section{Nutrition planning}

Nutrition and National Policy. Edited by Beverley Winikoff, Pp. 580. (MIT Press: Cambridge, Massachusetts, and London, UK, 1979.) $£ 15.75$.

THIS book is a monument to nutrition planning, the latest enthusiasm to sweep the nutrition profession as it looks desperately for some effective action with which to improve the health problems of developing countries.

Nutrition planning is a controversial approach the more coherent advocates of which argue that protein energy malnutrition in children must not be seen simply as a disease entity demanding clinical treatment. It is a disease of the poorest of the poor, a symptom of deprivation, the product of a lack of wealth and welfare which can only be eliminated by action at the economic level. As the object of development planning is to help reduce these same inequalities, three important consequences follow. Nutritional status will be improved by successful development strategies, and the improvement in nutritional status must be one of the objectives of a good development policy. Conversely, the extent of malnutrition serves as an

- In the review of Atomic Absorption Spectroscopy (see Nature, 280, 705; 1979), the author's name was incorrectly quoted. This should have read M. Slavin.

- Origins: What New Discoveries Reveal about the Emergence of Our Species and Its Possible Future (for review, see Nature, 270, 108; 1977), by Richard Leakey and Roger Lewin, has been published in paperback by Macdonald and Jane's (London, UK). the symbols" (page 245). Whether we are annoyed by his opinionated view of history or enthralled by his enthusiasm, we cannot fail to be fascinated and grateful for this chance to witness these lectures.

The editor, E. S. Pearson, has done an excellent job of piecing together the different versions of several lectures, furnishing a useful index and many notes, and cutting wisely where cutting was needed. The publishers must be congratulated for keeping the price at what must, for a volume of this size, be considered low. We may hope that this encourages many scientists (not only statisticians) to make the acquaintance of the extraordinary Karl Pearson.

Stephen M. Stigler is a Professor in the Department of Statistics at the University of Chicago, Illinois.

indicator of the effectiveness of those programmes.

This approach is one that I and many of my colleagues find acceptable. Many others do not agree, finding it unrealistic or unnecessary. These are legitimate differences in opinion, a source of mutual respect and a fruitful academic dialogue.

Unfortunately, although nutrition planning is an exciting theory, it is also a popular idea. The concept of nutrition planning has not been accepted but the image has, and this has become the portmanteau justification of tarted up versions of the same tired old theories that failed in the past. Sadly, ideas change slowly: they are simply renamed and thereby extended.

From all this comes, I assume, this book - almost 600 pages of mostly unnecessary prose with all too few passages that are worth reading. Twothirds of the book are devoted to "case studies' of national nutrition policies largely by the representatives of various developing countries. Apart from a brilliant study of malnutrition in Chile by G. Solimano and P. Hakim, which is a précis of their book (Development, Reform, and Malnutrition in Chile, MIT Press; for review, see Nature, 276, 542; 1978) on this topic, these national presentations are mediocre indeed. If nutrition students presented, as their view on nutrition planning, the hotch potch of miscellaneous data that seem to satisfy some of these planners they would fail their degrees. Why then are they included here? One possible reason lies in the origins of the book, which is the edited proceedings of a conference funded by the Rockefeller Foundation which took place at a Rockefeller mansion in Bellagio, Italy in 1975.

There is a growing tendency in international jamborees devoted to such areas of nutrition to invite participants not by eminence, or relevance, but by race. This may be politically expedient, but it is bad for science, and ultimately insulting to those who only get invited as statutory representatives of the third world. I do not know how far this consideration governed the structuring of this meeting, but, distasteful though the idea is, it would explain the quality of the papers selected, which add little to human understanding and detract from the science of nutrition.

It seems to me that nutritionists in government should at least have details of the prevalence of malnutrition in their countries, and changes in that rate with development policy. No such luck. If these authors are really reporting the understanding of nutrition planners in their countries, then either systematic data is not being collected, or no-one exploits it in the way that is surely a precursor to its use in the political decision making process.

We do not need them to report over and over again that malnutrition occurs in children, or even that the poor are nutritionally worse off than the rich. Such information is not in doubt. It is clear that the poor suffer. What is also clear is that even at the worst not all the poor are malnourished. Nutrition planning will only proceed effectively when the political decision makers are given some idea of which socially or ecologically defineable groups are at greatest risk, so that social policy can then be designed to help those groups.

In this book economic and nutritional information is presented in abundance, but it is presented neither within a framework that presupposes such action nor in the form that can be used by the reader to develop his own theories. I cannot imagine a politician being interested in such ramblings. These are not case studies they are travelogues compounded of largely uncollated nutritional and economic data, and peppered with politically tactful remarks.

When the book gets on to generalisations it improves somewhat, but still says little at great length. Towards the end it is suggested that Hong Kong, Singapore, South Korea and Japan have radidly improved nutritional status as a result of income redistribution. I am not convinced, but given that it is even tenable why doesn't the Rockefeller Foundation now fund a less lavish session to discuss the situation in these countries. If it were done coherently, those of us interested in this proposition could see whether given the political will, economics alone was the answer to nutritional problems. That at least would provide a test of the nutrition planning hypothesis in a way that the present volume notably fails to do.

John Rivers

John Rivers is Lecturer in the Department of Human Nutrition at the London School of Hygeine and Tropical Medicine, London, UK. 